\title{
Papers
}

\section{Congenital toxoplasmosis: systematic review of evidence of efficacy of treatment in pregnancy}

\author{
Martine Wallon, Christiane Liou, Paul Garner, François Peyron
}

\begin{abstract}
Objective To summarise the evidence that treating toxoplasmosis in pregnancy reduces the risk of congenital toxoplasma infection and improves infant outcomes.

Design Systematic review of studies comparing at least two concurrent groups of pregnant women with proved or likely acute toxoplasma infection in which treatments were compared with no treatment and outcomes in the children were reported.

Subjects Studies were identified from Medline (1966-97), Pascal (1990-7), Embase (1993-7), and Biological abstracts (1993-5) plus contact with experts in the field, including the European Research Network on Congenital Toxoplasmosis. Main outcome measure Proportion of infected children at 1 year born to infected pregnant women who were or were not treated.

Results Out of 2591 papers identified, nine met the inclusion criteria. There were no randomised comparisons, and control groups were generally not directly comparable with the treatment groups. Congenital infection was common in treated groups. five studies showed that treatment was effective and four that it was not.

Conclusion It is unclear whether antenatal treatment in women with presumed toxoplasmosis reduces congenital transmission of Toxoplasma gondii.

Screening is expensive, so the effects of treatment and impact of screening programmes need to be evaluated. In countries where screening or treatment is not routine, these technologies should not be introduced outside carefully controlled trials.
\end{abstract}

\section{Introduction}

Toxoplasmosis infection during pregnancy can cause congenital infection and manifest as mental retardation and blindness in the infant. ${ }^{1}$ Doctors prescribe spiramycin and sulphonamide for presumed infection to reduce mother to child transmission and the severity of fetal infection. These practices arose from reports of antiparasitic effects in vitro, ${ }^{23}$ in AIDS patients, ${ }^{4}$ and in pregnancy. ${ }^{5} 6$

In 1978 and 1985 Austria and France implemented nationwide programmes to detect and immediately treat all toxoplasma infections during pregnancy. Women of unknown immune status are tested during the first trimester of pregnancy. French seronegative women are advised on good hygiene to avoid infection and retested monthly to detect seroconversion. Women with evidence of acute infection are given spiramycin, amniocentesis, and ultrasound examination. If the fetus is infected the women are given sulphonamides and pyrimethamine, which is usually withheld in the absence of fetal infection because of potential teratogenicity and bone marrow toxicity for the mother and fetus. ${ }^{7}$ Parents can also opt for termination if there is evidence of fetal macroscopic lesions. ${ }^{89}$ In France, an estimated $44 \%$ of pregnant women are regularly checked for seroconversion $^{10}$ and between 5625 and 8850 women are treated during pregnancy every year to prevent congenital toxoplasmosis.

Other countries have decided against routine repeated screening in serologically negative women during pregnancy. In the United States, experts judged that such a programme was not warranted because of the low frequency of maternal infection and low chance of infection in the newborn. ${ }^{11}$ A UK working group of experts concluded in 1991 that "screening for acute toxoplasmosis in pregnancy should not be offered routinely." ${ }^{12}$

Opponents to systematic screening also point out the need for improved diagnostic tests-even since the development of polymerase chain reaction tests ${ }^{13}$-and the issue of cost effectiveness. ${ }^{14}{ }^{15}$ Detection of infection will have no effect unless the treatments given as a result of the screening actually reduce congenital infection and improve infant outcomes. We conducted a systematic review of the effects on the fetus and infant of treating women who seroconvert during pregnancy. ${ }^{16}$

\section{Methods}

\section{Inclusion criteria}

We included studies of pregnant women with toxoplasma infection, defined by an increase in specific IgG titres from paired sera or by a high titre of specific IgG at the first antenatal test. Studies based on specific IgM screening were excluded. Women could have been tested as part of a formal screening programme or through incidental testing carried out by general practitioners suspecting toxoplasmosis infection. All the included studies had to compare at least two groups of pregnant women, one of which received no antibiotic

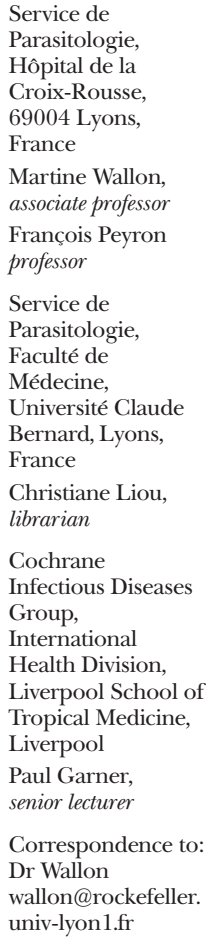

BMJ 1999;318:1511-4 
Details of included studies of treatment of toxoplasmosis in pregnant women

\begin{tabular}{|c|c|c|c|c|c|c|c|c|c|}
\hline Study & Trimester & Inclusion criteria & Selection of controls & $\begin{array}{l}\text { Quality } \\
\text { score }\end{array}$ & Regimen & $\begin{array}{l}\text { No of } \\
\text { infected } \\
\text { children }\end{array}$ & $\begin{array}{l}\text { No not } \\
\text { infected }\end{array}$ & $\begin{array}{l}\text { No lost to } \\
\text { follow up }\end{array}$ & $\begin{array}{c}\% \text { Infected } \\
\text { children }(95 \% \mathrm{CI})\end{array}$ \\
\hline \multirow[t]{2}{*}{$\begin{array}{l}\text { Desmonts and } \\
\text { Couvreur }^{21}\end{array}$} & \multirow[t]{2}{*}{ All } & \multirow{2}{*}{$\begin{array}{l}\text { Seroconversion; } \\
\text { significant increase in } \\
\text { IgG; clinical signs and } \\
\text { high levels of } \lg G\end{array}$} & \multirow{2}{*}{$\begin{array}{l}\text { Unknown; historical controls } \\
\text { (seroconversion diagnosed } \\
\text { retrospectively, after } \\
\text { delivery) }\end{array}$} & \multirow[t]{2}{*}{3} & $\begin{array}{l}\text { Spiramycin (2-3 g/day) for at } \\
\text { least } 1 \text { month: } 388\end{array}$ & 88 & 297 & 3 & 22 (18 to 27 ) \\
\hline & & & & & No treatment: 154 & 85 & 60 & 9 & $52(44$ to 60$)$ \\
\hline \multirow[t]{2}{*}{ Douche et $\mathrm{al}^{18}$} & \multirow[t]{2}{*}{ All } & \multirow[t]{2}{*}{ Seroconversion } & \multirow[t]{2}{*}{$\begin{array}{l}\text { Late seroconversions } \\
\text { Inadequate follow up }\end{array}$} & \multirow[t]{2}{*}{4} & $\begin{array}{l}\text { Spiramycin (2g/day): } 64 \\
\text { spiramycin + pyrimethamine }+ \\
\text { sulphadiazine after positive fetal } \\
\text { diagnosis: } 5\end{array}$ & 9 & 60 & 0 & 13 (6 to 24$)$ \\
\hline & & & & & No treatment: 29 & 29 & 0 & 0 & 100 (63 to 100$)$ \\
\hline \multirow[t]{7}{*}{ Excler et $\mathrm{al}^{20}$} & \multirow[t]{2}{*}{ First } & \multirow{2}{*}{$\begin{array}{l}\text { Seroconversion; increase } \\
\text { in } \lg G\end{array}$} & \multirow[t]{2}{*}{ Unknown } & \multirow[t]{2}{*}{2} & Spiramycin (3 g/day): 31 & 2 & 29 & 0 & 6 (1 to 23) \\
\hline & & & & & No treatment: 4 & 0 & 4 & 0 & $0(0$ to 60$)$ \\
\hline & \multirow[t]{2}{*}{ Second } & & & & Spiramycin: 55 & 15 & 40 & 0 & 27 (16 to 41$)$ \\
\hline & & & & & No treatment: 13 & 5 & 8 & 0 & 38 (15 to 68$)$ \\
\hline & \multirow[t]{2}{*}{ Third } & & & & Spiramycin: 18 & 5 & 13 & 0 & 28 (11 to 54$)$ \\
\hline & & & & & No treatment: 13 & 9 & 4 & 0 & 69 (39 to 90$)$ \\
\hline & All & & & & No treatment: 30 & 14 & 16 & 0 & 47 (29 to 65$)$ \\
\hline \multirow[t]{2}{*}{ Knerer et al ${ }^{19}$} & \multirow{2}{*}{$\begin{array}{l}14-29 \\
\text { week }\end{array}$} & \multirow[t]{2}{*}{ Seroconversion } & \multirow{2}{*}{$\begin{array}{l}\text { Untreated patients or } \\
\text { non-compliers }\end{array}$} & \multirow[t]{2}{*}{4} & Spiramycin (3 g/day): 9 & 0 & 9 & 0 & $0(0$ to 37$)$ \\
\hline & & & & & No treatment: 2 & 2 & 0 & 0 & $100(20$ to 100$)$ \\
\hline \multirow[t]{2}{*}{ Kräubig et al ${ }^{25}$} & \multirow[t]{2}{*}{ All } & \multirow{2}{*}{$\begin{array}{l}\text { Seroconversion (18); } \\
\text { increase }(x 2) \text { dye test; } \\
\text { dye test >1000 }\end{array}$} & \multirow[t]{2}{*}{ Unknown } & \multirow[t]{2}{*}{4} & Pyrimethamine+sulphonamide: 59 & 3 & 56 & 0 & $5(1$ to 15$)$ \\
\hline & & & & & No treatment: 84 & 14 & 70 & 0 & 17 (10 to 27$)$ \\
\hline \multirow[t]{2}{*}{ Lambotte et al ${ }^{23}$} & \multirow[t]{2}{*}{ All } & \multirow[t]{2}{*}{ Seroconversion } & \multirow{2}{*}{$\begin{array}{l}\text { Untreated patients or } \\
\text { non-compliers }\end{array}$} & 4 & Spiramycin + sulphadiazine & 0 & 28 & 0 & $0(0$ to 15$)$ \\
\hline & & & & & No treatment: 101 & 10 & 91 & 0 & 10 (5 to 18$)$ \\
\hline Roux et al ${ }^{22}$ & All & Seroconversion (10); & Late seroconversions (5) & 3 & Spiramycin (3 g/day): 47 & 2 & 43 & 2 & $4(0.7$ to 15$)$ \\
\hline & & high IgG titres (25) & & & No treatment: 6 & 5 & 1 & 0 & 83 (36 to 99$)$ \\
\hline Thoumsin et $\mathrm{al}^{24}$ & All & Seroconversion & Unknown & 2 & $\begin{array}{l}\text { Spiramycin + pyrimethamine + } \\
\text { suphadiazine (dose unknown): } 99 \\
\end{array}$ & 10 & 89 & 0 & 10 (5 to 8$)$ \\
\hline & & & & & No treatment: 101 & 10 & 91 & 0 & 10 (5 to 20$)$ \\
\hline Wallon et $\mathrm{al}^{26}$ & All & Seroconversion & $\begin{array}{l}\text { Lyons: No controls } \\
\text { Copenhagen: screening at } \\
\text { delivery }\end{array}$ & 4 & $\begin{array}{l}\text { Spiramycin }(3 \mathrm{~g} / \text { day }) \pm \\
\text { pyrimethamine and } \\
\text { sulphadiazine: } 564\end{array}$ & 141 & 381 & 42 & 24 (20 to 27$)$ \\
\hline
\end{tabular}

* Increase in $\lg G$ and $\lg M$ titres or loss of $\lg M$ with stable or increasing $\lg G$ titre.

treatment. The drug, dose, and duration in the treatment group did not affect inclusion. Studies comparing treatments were excluded.

Congenital infection was defined as persisting specific IgG at age 1 year. Clinical infection was defined by the presence of: hydrocephalus, ventricle dilatation, intracranial calcifications, or chorioretinitis. Children with no clinical signs were considered disease free if seronegative at 1 year. Clinically disease free children without a negative test result were considered lost to follow up. Cases of abortion, stillbirth, or infant death with no evidence of toxoplasmosis infection were also considered as lost to follow up.

\section{Search strategy}

We performed an electronic search using the key words "congenital and toxoplasmosis" in four databases: Medline (1966-07/1997), Embase (1993-07/ 1997), Pascal (French) (1990-1997), and Biological abstracts (1993-1995). References of the papers identified were scanned for additional relevant studies. Members of the European Research Network on Congenital Toxoplasmosis and other experts were asked for relevant published or unpublished data.

The abstract and title of each of the 2591 papers thus identified were checked by two people independently and all papers dealing with animal models, biological aspects of the disease, congenitally infected children without data on pregnancy, and isolated case reports were excluded. We obtained hard copies of the studies that potentially met the inclusion criteria.

\section{Data extraction and analysis}

Papers that potentially met the inclusion criteria were scrutinised a second time by two people. Information was extracted by using a data extraction sheet, and this included the entry criteria, the source of the controls, and whether the authors stratified by stage of pregnancy when the infection occurred. We assessed the quality of studies using a scale ranging from 0 to 6 , based on six equally weighted items: randomised group allocation, recruitment at the same location for both groups, recruitment during the same period for both groups, analysis based on the intention to treat, inclusion in the analysis of patients lost to follow up, and if cases lost to follow up were included, that they constituted less than $10 \%$ of the total sample and were adequately taken into account. Each item was scored 1 for "yes" and 0 for "no" or "unknown."

Criteria for maternal infection were divided into true seroconversion and infections that were suspected because of significant increase in IgG titres but could not be proved because the first available sample was already positive for IgG. Cases lost to follow up were included successively as non-infected and infected, and low and high transmission rates were estimated. Statistical analyses were reviewed based on the published figures (Epi-info 6.2, ${ }^{17}$ ). 


\section{Description of studies}

We identified 305 studies to consider for inclusion, but only nine met our predetermined criteria (table). The paper by Desmonts and Couvreur in $1984^{21}$ contained data previously published in 1974, so the earlier paper was excluded. Eight studies were published, ${ }^{18-25}$ and one was available only as an abstract. ${ }^{26}$ Reports were from France (four), Belgium (two), Germany (one), and Austria (one), with one French-Danish collaboration. In seven reports, women were participating in a routine screening programme. In the other two reports, subjects were recruited through screening or individual testing by their doctor. The number of included subjects ranged from $11{ }^{19}$ to $689 .{ }^{26}$ None of the studies included randomised comparisons between women.

\section{Results}

Five studies reported significantly lower transmission rates in children born to treated mothers $(\mathrm{P}<0.01){ }^{18-22}$ Maternal treatment was with spiramycin alone in four studies. Douche et al added sulphonamides to spiramycin after fetal infection was diagnosed antenatally. ${ }^{18}$ Suspected but unproved maternal infections were included in three studies. ${ }^{20-22}$ The date of maternal infection was taken into account in only one study. ${ }^{20}$ Trimester specific analysis indicates that the reduction in transmission was mainly attributable to treatment efficacy in women who seroconverted during the third trimester of pregnancy. Children were followed for at least 12 months in three studies, ${ }^{18-20} 10$ months in one ${ }^{21}$ and 6 months in one. ${ }^{22}$

Four studies reported no reduction of fetal infection in the treated groups. ${ }^{23-26}$ Sulphonamides or pyrimethamine, or both, were added to spiramycin in three studies ${ }^{2324}$ and used alone in the fourth. ${ }^{25}$ Unproved seroconversions were included in one study. ${ }^{25}$ None of the studies took into account the date of maternal infection. Only two reports mentioned the source of the controls. In one, the control group was a mixture of women diagnosed with toxoplasmosis who did not take the recommended treatment and women whose "obstetrician lacked conviction." ${ }^{\text {3 }}$ In the second, a Danish cohort of untreated women with proved seroconversion was used as controls. ${ }^{26}$ Seroconversion was not tested for until delivery, which explains the absence of antenatal treatment. Because the date of maternal infection was not known in the Danish group, there is no evidence that the controls were comparable with the intervention group. The length of postnatal follow up was at least 1 year in all four studies. In two studies the authors concluded that the treatment worked, ${ }^{23}$ although our analysis of the available data did not show any difference.

The quality score was 2 in two studies, ${ }^{20}{ }^{24} 3$ in two studies, ${ }^{2122}$ and 4 in five, ${ }^{18} 19232526$; no studies scored 6 (table). Three of the five studies suggesting a beneficial effect of treatment scored less than $4,{ }^{20-22}$ whereas only one of the four studies that found no effect scored less than four. ${ }^{24}$

\section{Discussion}

Ideally, policies for managing women who develop toxoplasmosis in pregnancy should be based on good research. Studies should randomly allocate women who seroconvert in pregnancy to an intervention or control group, should be large enough to give sufficient power, and should follow up children to a point when congenital toxoplasmosis can be excluded. None of the 2591 papers published over the past 30 years fulfilled all these criteria.

Despite our broad inclusion criteria, only a few studies included controls. The controls that were used were often not directly comparable with the treatment group: some controls were women who failed to comply with the antibiotic instructions; women who seroconverted in late pregnancy; or women from populations unrelated to those in the intervention group. In other studies, it was not clear where the controls came from. Date of seroconversion is likely to influence the effects of the infection and of treatments, but this was taken into account in only one paper. ${ }^{20}$ Only five studies were based on pregnant women with proved seroconversion. None of these studies gave details of the delay between infection and onset of treatment, and details of the treatment were not always available. The outcome assessment was satisfactory in seven studies. Even in the intervention groups, treatment failures are relatively common, with congenital infection occurring in a third to a fifth of cases. Although the rate of infection was higher in the control groups, our inability to assess or otherwise quantify the lack of comparability of the control groups makes interpretation difficult.

\section{Implications for policy}

In our opinion, current evidence is insufficient to confirm that treating mothers who seroconvert during pregnancy prevents fetal infection and improves infant outcomes. We are not saying that there is no such benefit but that current research is inadequate to assess whether the putative benefits outweigh the potential harm of the drugs to the fetus.

We did not examine potential indirect benefits of screening. Serological testing early in pregnancy allows health professionals to advise seronegative women on avoiding infection. Immune women can be reassured and excluded from further testing. Identifying acute infection through repeated antenatal tests facilitates fetal diagnosis through polymerase chain reaction amplification of DNA in amniotic fluid and ultrasonography to monitor fetal development. If infection is confirmed, the parents have the options of termination of pregnancy in the case of morphological lesions or experimental, in utero treatment with sulphonamides and pyrimethamine. Treatment and surveillance can be continued immediately after birth.

\section{Implications for research}

Further studies are needed to evaluate the benefits of maternal treatment schedules. They should use standardised interventions and outcome measures and be based on proper randomisation.

Countries which do not currently perform systematic screening should conduct appropriate research before introducing screening. A large study could randomise healthcare clinics to no screening (existing practice) or screening with follow up of seronegative patients and treatment if they convert. Only then will it 
Key messages

- Pregnant women in France and Austria are routinely screened for toxoplasmosis, and women negative for antibodies are followed up at regular intervals

- The value of antenatal toxoplasmosis screening programmes depends on safe treatments that reduce the risk of congenital disease

- This systematic review found no good comparative data measuring the potential harms and benefits of antiparasitic drugs used for presumed antenatal toxoplasma infection

- Most control groups were not comparable, and incidence of congenital infection was high in the intervention groups

- Countries considering introducing screening should do so only in the context of a controlled trial

be possible to know whether the package of care is effective in preventing congenital toxoplasmosis.

In countries where screening is routine, assessment will be more difficult because of the conviction of health professionals and the public's belief in screening. Congenital infection remains a problem despite intervention, and it would be possible to conduct randomised trials of different treatment regimens. France and Austria have been expected by many other countries to produce evidence of the benefits of national screening programmes. Ironically, they will depend on other countries to demonstrate the cost effectiveness of their screening programmes.

This review has been submitted to Pregnancy and Childbirth collaborative review group and a longer version of it will be maintained in the Cochrane Library.

We thank Abdullahi Addo, Catherine Cozon, Josette Ferrandiz, Agnes Igo-Kemenes, Sandrine Kahi, Ming Lo, and Magdalen Robaczenska for translation of papers.

Contributors: FP and PG were responsible for the conception of the study and the original protocol draft. MW, CL, and FP were responsible for identifying the papers, extracting and synthesising the data, and writing the first draft. All authors took part in its revision and approved the final version. FP is the study guarantor.

Funding: This study was supported by a grant from the European Union Directorate General XII, and the Cochrane Infectious Diseases Group is supported by the Department for International Development (UK). The funding bodies take no responsibility for the data presented and the views expressed.

Competing interests: None declared.
1 Hohlfeld P, Daffos F, Thulliez P, Aufrant C, Couvreur J, MacAleese J, et al. Fetal toxoplasmosis: outcome of pregnancy and infant follow-up after in utero treatment. J Pediatr 1989;115:765-9.

2 Garin JP, Paillard B. Toxoplasmose expérimentale de la souris. Activité comparée de clindamycine, midécamycine, josamycine, spiramycine, pyriméthamine-sulfadoxine et triméthoprime-sulfaméthoxazole. Ann

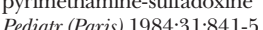

3 Sheffield HG, Melton ML. Effect of pyrimethamine and sulfadiazine on the fine structure and multiplication of toxoplasma gondii in cell cultures. J Parasitol 1975;61:704-12.

4 Porter SB, Sande MA. Toxoplasmosis of the central nervous system in the acquired immunodeficiency syndrome. N Engl J Med 1992;327:1643-8.

5 Desmonts G, Couvreur J. Toxoplasmosis in pregnancy and its transmission to the fetus. Bull N Y Acad Med 1974;50:146-59

6 Desmonts G, Couvreur J. Congenital toxoplasmosis. N Engl J Med 1974;290:1110-6.

7 Remington JS, McLeod R, Desmonts G. Toxoplasmosis. In: Remington $\mathrm{JS}$, Klein JO, eds. Infectious diseases of the fetus and newborn infant. 4th ed. Philadelphia:JB Lippincott, 1992:349-64.

8 Berrebi A, Kobuch WE, Bessieres MH, Bloom MC, Rolland M, Sarramon MF, et al. Termination of pregnancy for maternal toxoplasmosis. Lancet 1994;344:36-9.

9 Wallon M, Gandilhon F, Peyron F, Mojon M. Toxoplasmosis in pregnancy. Lancet 1994;344:541.

10 Ancelle T, Goulet V, Tirard-Fleury V, Baril L, Du Mazaubrun C, Thulliez PH, et al. La toxoplasmose chez la femme enceinte en France en 1995. Bull Epidemiol Hebdomadaire (Paris) 1996;51:227.

11 Bader TJ, Macones GA, Asch DA. Prenatal screening for toxoplasmosis. Obstet Gynecol 1997;90:457-64.

12 Royal College of Obstetricians and Gynaecologists: Prenatal screening for toxoplasmosis in the UK. Report of a multidisciplinary working group. London: RCOG, 1992.

13 Hohlfeld P, Daffos F, Costa JM, Thulliez P, Forestier F, Vidaud M. Prenatal diagnosis of congenital toxoplasmosis with a polymerase-chain-reaction test on amniotic fluid. N Engl J Med 1994;331:695-9.

14 Eskild A, Oxman A, Magnus P, Bjorndal A, Bakketeig LS. Screening for toxoplasmosis in pregnancy: what is the evidence of reducing a health problem? J Med Screening 1996;3:188-94.

15 Jeannel D, Costagliola D, Niel G, Hubert B, Danis M. What is known about the prevention of congenital toxoplasmosis? Lancet 1990;336:359-61.

16 Peyron F, Wallon M, Bernadoux C. Long-term follow-up of patients with congenital ocular toxoplasmosis. N Eng J Med 1996;334:993-4

17 Dean AG, Dean JA, Coulombier D, Brendel KA, Smith DC, Burton AH, et al. Epi Info version 6: a word processing, database, and statistics program for public health on microcomputers. Atlanta: Centers for Disease Control and Prevention, 1995.

18 Douche C, Benabdesselam A, Mokhtari F, Le Mer Y. Value of prevention of congenital toxoplasmosis. J Fr Ophtalmol 1996;19:330-4.

19 Knerer B, Hayde M, Gratz G, Bernaschek G, Strobl W, Pollak A. Direct detection of Toxoplasma gondii with polymerase chain reaction in diagnosis of fetal toxoplasma infection. Wien Klin Wochenschr 1995;107:13740.

20 Excler JL, Piens MA, Maisonneuve H, Pujol E, Garin JP. Dépistage de la toxoplasmose acquise chez la femme enceinte et de la toxoplasmose congénitale chez le nouveau-né. Lyon Med 1985;253:33-8.

21 Desmonts G, Couvreur J. Toxoplasmose congénitale. Ann de Pediatr (Paris) 1984;31:805-9.

22 Roux C, Desmonts G, Mulliez N, Gaulier M, Tufferaud G, Marmor D, et al. Toxoplasmosis and pregnancy. Evaluation of 2 years of prevention of congenital toxoplasmosis in the maternity ward of Hôpital Saint-Antoine (1973-1974). J Gynecol Obstet Biol Reprod (Paris) 1976;5:249-64.

23 Lambotte R, Bassleer J, Beaudouin PH, Senterre J, Lhoist R. Toxoplasmose congénitale: évaluation du bénéfice thérapeutique prénatal.J Gynecol Obstet Biol Reprod (Paris) 1976;5:265-9.

24 Thoumsin H, Senterre J, Lambotte R. Twenty-two years of screening for toxoplasmosis in pregnancy: Liege-Belgium. Scand J Infect Dis 1992;84(suppl):84-5.

25 Kräubig H. Präventive Behandlung der konnatalen Toxoplasmose. In: Kirchhoff $\mathrm{H}$, Kräubig $\mathrm{H}$, eds. Toxoplasmose. Praktische Fragen und Ergebnisse. Stuttgart: Georgthieme Verlag, 1966.

26 Wallon M, Peyron F, Lebech M, Petersen E, Gilbert R, Dunn D. Prenatal treatment and the risk of congenital toxoplasmosis: preliminary findings from two cohort studies [abstract No 94.] European Society for Research in Pediatrics annual meeting, Szedeg, Hungary 1997. Pediatr Res 1997;42:400.

(Accepted 24 February 1999)

\section{One hundred years ago Medical practitioners and the plague duty in India}

More medical practitioners are badly wanted in India for plague duty, and we are informed that the India Office finds it difficult to get them. This is scarcely to be wondered at, considering that the remuneration offered for a service involving special risks and considerable hardship is only 700 Rs. per mensem-roughly $£ 46$ at 15 Rs. to the $£$, the present exchange. The minimum period of stay in India is nine months, the Government being able to shorten that period at its discretion; as, for instance, should plague be stamped out and no further need be had of the doctor's services; or, on the other hand, he can volunteer for a further period of duty. No leave is given. A period of nine months of plague duty, either in city, hospital, or segregation camp, is surely worthy of more remuneration than is at present attached to it. (BMJ 1899;ii:670) 